\title{
Are Frequent Callers to Family Physicians High Utilizers?
}

\author{
David E. Hildebrandt, $P b D^{1}$ \\ Jobn M. Westfall, MD, MPH \\ Richard A. Nicholas, $M D^{1}$ \\ Peter C. Smith, $M D^{1}$ \\ Jacqueline Stern, $M D^{2}$ \\ 'Department of Family Medicine, University \\ of Colorado Health Sciences Center \\ at Fitzsimons, Aurora, Colo \\ ${ }^{2}$ Department of Family Medicine, Rose \\ Family Medicine Residency, Denver, Colo
}

\begin{abstract}
PURPOSE Our objective was to describe patients who telephone frequently after hours to physicians (frequent callers) and categorize their medical problems and resource utilization.

METHODS Charts of frequent callers were reviewed and compared with those of a systematically selected group from the same family medicine residency practice (control group). Data collected included demographic and clinical information, as well as information on utilization of office, emergency department, and hospital services. In addition, 4 family physicians reviewed the patient information and identified the primary diagnosis for frequent callers.
\end{abstract}

RESULTS Frequent callers were predominately female; had 3 times as many office visits, diagnoses, and medications; and had 8 times as many hospital admissions as the control group. The most common primary diagnostic categories were psychiatric disorders (36\%), pain (21\%), chronic illnesses (16\%), pregnancy (13\%), and common problems of childhood (9\%).

CONCLUSIONS Frequent callers represent a unique group of patients with high utilization of health care services. Better targeted patient education and referral to other support services may decrease the number of calls and utilization of health services. Alternatively, among high utilizers, frequent telephone calls may be a substitute for other forms of care.

Ann Fam Med 2004;2:546-548. DOI: 10.1370/afm.127

\section{INTRODUCTION}

$\tau$ $\mathrm{n}$ a previous study ${ }^{1}$ we identified a small group of patients $(0.6 \%$ of all patients) in a Denver, Colo, family medicine residency practice that accounted for $23 \%$ of all after-hours telephone calls. These frequent callers averaged nearly 10 calls per year in contrast with an average of 1 call per year for all other callers. Health services researchers typically identify high utilizers by their number of visits to the office. ${ }^{2-4}$ Patients who come to the office frequently have been described as older, divorced or widowed, members of lower socioeconomic groups, anxious and depressed, and having multiple physical and psychosocial ills and medically unexplained symptoms. ${ }^{5,6}$ The purpose of this study was to describe frequent after-hours callers, categorize their medical problems, and examine their resource utilization.

\section{METHODS}

The complete outpatient medical record of frequent callers and a comparison group were carefully examined for all office contacts between April 2000 and March 2001. When the caller was not the patient (parent, spouse, caretaker, etc), we used the identified patient's chart. Three charts of frequent callers could not be located and were not included in further analysis. The first author used a standardized chart abstraction 
instrument to determine age, sex, number of office visits, number of diagnoses listed on the problem list, and details of prescribed medications. The practice had approximately 12,000 active patients (at least 1 visit to the practice in the last 2 years) with about 1,350 patient visits per month. Approximately 30\% were insured by Medicaid, $10 \%$ by Medicare, 35\% by a health maintenance organization/preferred provider organization, and $12 \%$ by a third party payer; $13 \%$ were uninsured.

Data were entered into an Access database. Medications were categorized as prescribed for pain, psychiatric, or other based on the indications listed in the treating physician's charted note. For example, amitriptyline for chronic pain would be categorized as pain medicine, not psychiatric medicine. We collected data in the same manner from emergency department, hospital admission, and discharge notes available in the electronic database of the residency-affiliated hospital system. For the comparison group, we selected every 100th chart from approximately 12,000 charts of active patients. We tested the null hypothesis of no difference between frequent caller and control groups using the Student $t$ test for comparison of means and chi-square analysis for categorical data (SAS v8.0, SAS Institute, Cary, NC).

Four physicians reviewed the Access database to answer the question, "What is the primary diagnosis related to this person calling so frequently?" Panel physicians were board-certified, residency faculty with an average of 12 years' postresidency experience (range 6 to 20 years). We used a modified Delphi $\operatorname{method}^{7}$ to determine the primary diagnosis for frequent callers. The Health One Institutional Review Board approved the study.

\section{RESULTS}

Table 1 displays the results of our review of patient records. Compared with the control group, frequent callers were more often female. They averaged 3 times more office visits and diagnoses, 10 times more emergency department visits, and 8 times more hospital admissions than the comparison group. Frequent callers had 3 times as many prescriptions on their medication lists as the control group, and higher proportions of these prescriptions were for psychiatric and pain medications ( $25 \%$ vs $15 \%$, respectively).

Table 2 displays the results of the review our physician panel made of the frequent callers' database. The primary diagnostic categories were psychiatric disorders, pain-related diagnoses, chronic illness, pregnancy or gynecologic disorders, and childhood illnesses or fever.

\section{DISCUSSION}

We aimed to describe patients who call frequently after hours, categorize their medical problems, and determine their utilization of health services. Our frequent callers closely mirror patients with high rates of office utilization. ${ }^{3}$ They are often female patients who are suffering from anxiety, depression, chronic illnesses, or pain. They go to the emergency department and are hospitalized more frequently. Our findings suggest that monitoring the frequency of after-hours telephone calls may identify patients at risk for high utilization of services.

Targeted interventions for these patients may decrease the excess demand. Identified frequent callers might benefit from alternative modes of care, especially for symptoms of anxiety, depression, and pain. Such strategies as more aggressive early diagnosis, group visits, more intensive therapy, and effective referral to mental health professionals can be helpful. Several studies $^{2,8}$ have suggested that more effective treatment of depression can lead to decreased health resources utilization. Just as targeting patients with diabetes for intensive case management can reduce the frequency of complications and improve care, ${ }^{9}$ so might similar interventions exert an analogous affect on frequent callers. Frequent telephone contact might represent a treatment option for patients with high health care needs

Table 1. Frequent Callers vs Control Subjects

\begin{tabular}{|c|c|c|c|}
\hline Variable (Mean) & $\begin{array}{c}\text { Frequent } \\
\text { Caller } \\
(n=53)\end{array}$ & $\begin{array}{c}\text { Control } \\
(n=122)\end{array}$ & $P$ Values \\
\hline Age, y & 30.2 & 30.7 & NS \\
\hline Female, \% & 81.0 & 52.0 & $<.001$ \\
\hline Diagnosis, $\mathrm{n}$ & 6.4 & 2.6 & $<.001$ \\
\hline Medications, $n$ & 7.7 & 2.7 & $<.001$ \\
\hline Psychiatric medications, $\mathrm{n}$ & 0.92 & 0.30 & $<.001$ \\
\hline Pain medications, $\mathrm{n}$ & 0.96 & 0.10 & $<.001$ \\
\hline Office visits in past year, $\mathrm{n}$ & 8.8 & 2.4 & $<.001$ \\
\hline $\begin{array}{l}\text { Emergency department } \\
\text { visits in the past year, } \mathrm{n}\end{array}$ & 1.2 & 0.1 & $<.001$ \\
\hline $\begin{array}{l}\text { Hospital admissions in the } \\
\text { past year, } n\end{array}$ & 2.4 & 0.3 & $<.001$ \\
\hline
\end{tabular}

Table 2. Summary of Frequent Callers' Diagnostic Groups

\begin{tabular}{lcc}
\hline Diagnostic Group & Number & Percent \\
\hline Psychiatric (depression, anxiety, etc) & 20 & 38 \\
Pain & 12 & 23 \\
Chronic medical illness & 9 & 17 \\
Pregnancy, gynecologic disorder & 7 & 13 \\
Childhood illness or fever & 5 & 9 \\
Total & 53 & 100 \\
\hline
\end{tabular}


and might substitute for care in other locations, such as the emergency department or office.

Several limitations may affect our study. It was conducted in one office setting, and the patient population might not be generalizable. In addition, patients in our study might have visited other emergency departments or have been hospitalized outside our hospital system. The system covers 8 hospitals in the Denver metropolitan area, however, and follow-up information should have been available in the outpatient paper record. In our experience, most of our patients use our residencyaffiliated hospital exclusively.

In conclusion, frequent callers are high utilizers of health resources. Further research should focus on effective design and implementation of programs that identify frequent callers and intervene with targeted education, proactive treatment, and intensive case management.

To read or post commentaries in response to this article, see it online at http://www.annfammed.org/cgi/content/full/2/6/546.

Key Words: Primary health care; triage; emergency medical services; health services

Submitted August 21, 2003; submitted, revised, January 6, 2004; accepted January 15, 2004.

\section{References}

1. Hildebrandt D, Westfall J. Reasons for after-hours calls. J Fam Pract. 2002;51:567-569.

2. Pearson D, Katzelnick D, Simon G, et al. Depression among high utilizers of medical care. J Gen Intern Med. 1999;14:461-468.

3. Lefevre F, Reifler D, Lee $P$, et al. Screening for undetected mental disorders in high utilizers of primary care services. J Gen Intern Med. 1999; 14:425-431.

4. Mehl-Madrona LE. Frequent users of rural primary care: comparison with randomly selected users. J Am Board Fam Pract. 1998;11:105115.

5. Reid S, Crayford T, Hotopf M. Medically unexplained symptoms in frequent attenders of secondary health care: retrospective cohort study. BMJ. 2001;322:767-769.

6. Smucker D, Zink T, Susman J, et al. A framework for understanding visits by frequent attenders in family practice. J Fam Pract. 2001;50:847-852.

7. Custer RL, Scarcella JA, Stewart BR. The modified delphi technique: a rotational modification. J Voc Tech Ed. 1999:15.

8. Katzelnick DJ, Simon GE, Person SD, et al. Randomized trial of a depression management program in high utilizers of medical care. Arch Fam Med. 2000;9:345-351.

9. Sutherland JE, Hoehns JD, O'Donnell B, Wiblin RT. Diabetes management quality improvement in a family practice residency program. J Am Board Fam Pract. 2001;14:243-251. 